\title{
Educação para a Morte
}

\author{
Education for death
}

Julia Kovács

Universidade de São Paulo

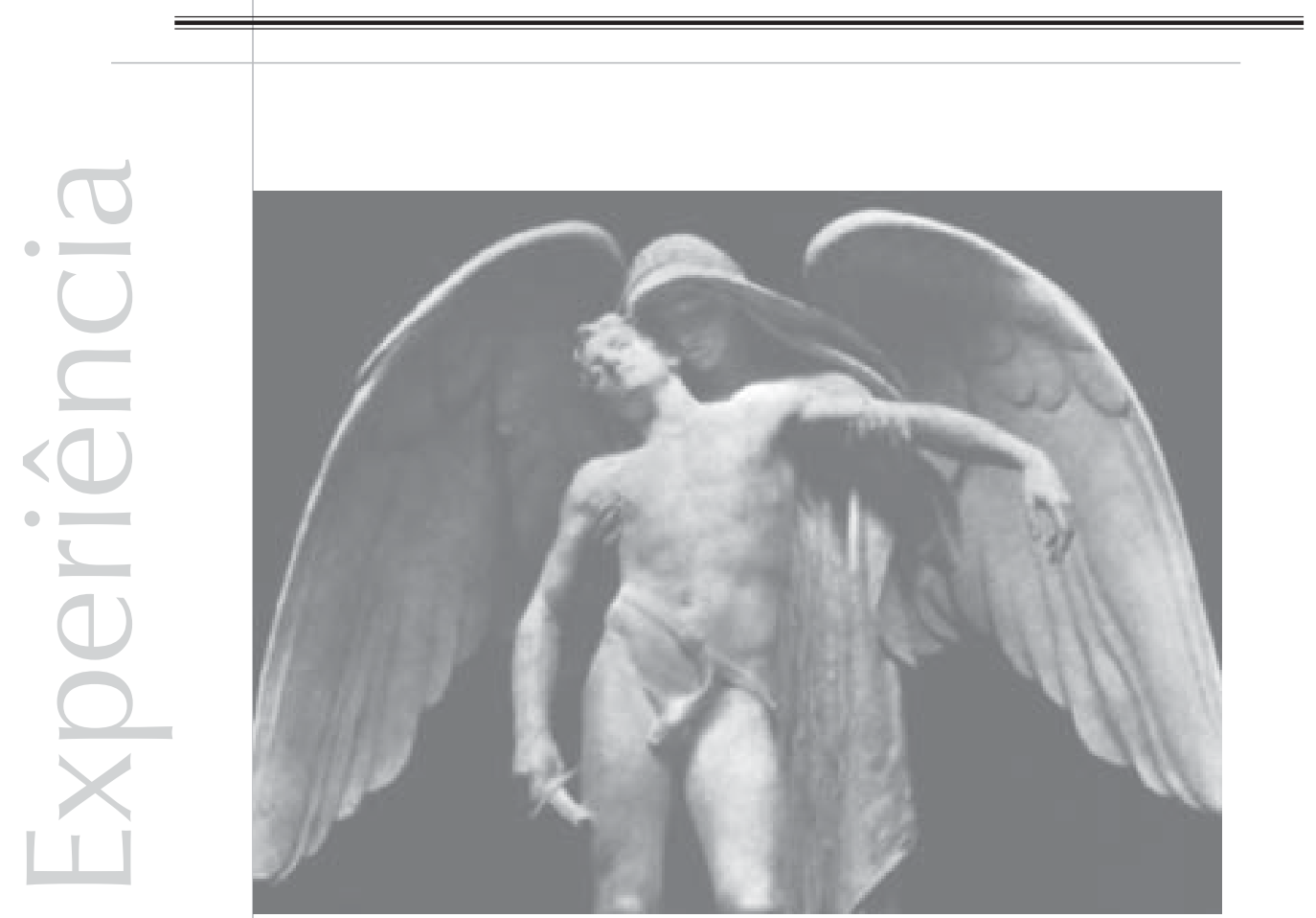


Resumo: A morte faz parte do desenvolvimento humano desde a mais tenra idade e acompanha o ser humano no seu ciclo vital, deixando suas marcas. Como preparar pessoas para esse fato tão presente na existência? Esse desafio é ainda mais urgente para os profissionais de saúde e educação. Perguntas têm assoberbado a humanidade, e respostas foram trazidas pelas religiões, ciências, artes, filosofias, entretanto, nenhuma delas é completa e universal. É sobre esses questionamentos e reflexões, sobre a busca de sentido à vida que a morte pode oferecer, sobre essa característica ou qualidade humana de questionamentos, de autoconhecimento, que pretendemos falar. A educação é entendida como desenvolvimento pessoal, aperfeiçoamento e cultivo do ser, que também pressupõe uma preparação para a morte, envolvendo comunicação, relacionamentos, perdas, situações-limite, como, por exemplo: fases do desenvolvimento, perda de pessoas significativas, doenças, acidentes, até o confronto com a própria morte. Serão discutidas várias propostas de educação para a morte tanto para o público leigo quanto para os profissionais.

Palavras-chave: morte, educação, profissionais de saúde e educação, luto.

Abstract:Death is part of the human development since the first years of life and goes along with the human being throughout the existence, leaving its marks. How could we prepare people to this subject so important in life? This is a challenge even more urgent to health and education professionals. Many questions overwhelm Humanity and answers are given by religions, sciences, arts and phylosophy, but none is universal. We shall consider these questions and reflections, the search for meaning, about life that the questions about death promote. Education here is understood as personal development, self improvement, and involves communication, relationships, losses, limit situations such as: development phases, loss of close people, diseases, accidents and confronting own death. Several death education formats will be discussed including layman and health and professionals' education.

Key words: death, education, health and education professionals, bereavement.

\section{Educação para a morte sugestões de linhas de ações para o psicólogo}

A morte faz parte do desenvolvimento humano desde a sua mais tenra idade e acompanha o ser humano no seu ciclo vital, deixando suas marcas. Questões são constantemente formuladas: "De onde viemos e para onde vamos?" "Será a morte o final da existência, ou somente transição, o final do corpo físico, a libertação da alma? Haverá outras vidas? Será a alma imortal? O espírito se mantém tal como o conhecemos? Será a nossa existência um caminhar para a evolução de cada ser? Chegaremos à perfeição divina? Como preparar pessoas para esse fato tão presente na existência? Esse desafio se torna ainda mais urgente para os profissionais de saúde e educação.

Considerando nossa existência terrena, quanto tempo viveremos e como será nossa vida? Teremos controle e poder sobre o nosso existir? Teremos o direito de saber sobre a nossa morte, como e quando será? Podemos nos preparar para esse momento? Estamos rodeados por um tecido cultural que determina, até certo ponto, como viveremos e como morreremos. Qual é o grau de 
liberdade, de ação, dentro desse tecido ou rede de valores, significados e representações? As perguntas continuam: por que pessoas jovens e saudáveis morrem rapidamente e pessoas idosas não o fazem? Por que pessoas adormecem e morrem no silêncio do sono, e outras lutam e se debatem até o último momento, com dores e sofrimentos atrozes? Por que pessoas se escondem da morte, não querem nem ouvir falar sobre o assunto? $\mathrm{E}$ por que outras riem, fazem piada sobre temas escatológicos? Por que tantos filmes sobre a morte, nos títulos ou na sua temática? Por que a morte exerce tanto fascínio sobre algumas pessoas, a ponto de seduzi-las? Por que é musa inspiradora de tantos: músicos, poetas, escritores, profissionais de saúde e educação? Tantas perguntas têm assoberbado a humanidade durante os tempos. Respostas foram trazidas pelas religiões, ciências, artes, filosofias, entretanto, nenhuma delas é completa e universal. São incompletas, embora possam ser, para algumas pessoas, num dado tempo, o que buscam, oferecendo, mesmo que provisoriamente, um sentimento de totalidade.

É sobre esses questionamentos e reflexões que pretendemos falar, sobre a busca de sentido à vida que a morte pode oferecer. É essa característica ou qualidade humana de questionamentos, de auto-conhecimento, de busca de sentido que procuraremos abordar, bem como a educação, entendida como desenvolvimento pessoal, aperfeiçoamento e cultivo do ser, e não como padrões de informação, receitas prontas ou doutrinação. Não temos uma resposta simples, única, total, dogmática e padronizada, e, sim, a possibilidade de busca inerente ao ser humano, que, mesmo esmagado por uma sociedade desumana e massificadora, pode florescer e desenvolver-se (Kovács, 2003). Educação para a morte é um estudo sobre a possibilidade do desenvolvimento pessoal de uma maneira mais integral, no sentido entendido por Jung (1960) como individuação, o desenvolvimento interior que se propõe durante o existir, desenvolvimento que também pressupõe uma preparação para a morte. Freqüentamos escolas por mais de vinte anos de nossa existência e assim nos preparamos para a vida social; da mesma forma, deveríamos também nos preparar, pelos mesmos "vinte anos", para o fim de nossa existência. Esse desenvolvimento não precisa ser realizado no topo de uma montanha, como ermitãos, ou dentro de casa isolados, e, sim, no seio da sociedade da qual somos membros integrantes. Essa educação envolve comunicação, relacionamentos, perdas, situações-limite, nas quais reviravoltas podem ocorrer durante a vida, como, por exemplo, fases do desenvolvimento, perda de pessoas significativas, doenças, acidentes, até o confronto com a própria morte.

O tema da morte se tornou interdito no século XX (Ariés, 1977), sendo banido da comunicação entre as pessoas. Paradoxalmente, nesse mesmo século, a morte esteve e continua estando, no início do século XXI, cada vez mais próxima das pessoas, em função, principalmente, do desenvolvimento das telecomunicações. A TV introduz diariamente, em milhões de lares, cenas de morte, de violência, de acidentes, de doenças, sem a mínima possibilidade de elaboração, dado o ritmo propositalmente acelerado desse veículo. Então, ao mesmo tempo em que é interdita, a morte torna-se companheira cotidiana, invasiva e sem limites, e, embora essas mortes estejam tão próximas (real ou simbolicamente), reina uma conspiração do silêncio. Crianças e adolescentes convivem com essas imagens diariamente, ao mesmo tempo em que se tenta "poupá-los" para não os entristecer.

Por outro lado, o surgimento e o aumento dos casos de AIDS e de câncer em crianças e adolescentes faz com que vivenciem o estar doentes, hospitalizados por longos períodos, privados de brincadeiras, dos amigos, das atividades escolares, das relações amorosas, 
da formação da identidade, ao mesmo tempo em que convivem com a perspectiva da morte. O desenvolvimento da tecnologia médica, os diagnósticos e tratamentos cada vez mais sofisticados trouxeram o prolongamento da vida, embora nem sempre tenhamos garantia da qualidade desta, principalmente no caso dos idosos.

Embora essas mortes estejam tão próximas, ocorre grave distúrbio na comunicação que denominamos conspiração de silêncio; observam-se pais que não sabem se devem falar ou não sobre a morte de um parente próximo, professores que se vêem às voltas com perguntas insistentes sobre mortes de ídolos, de pequenos companheiros, de amigos, e profissionais de saúde que se empenham numa luta de vida e morte contra as doenças, e que, muitas vezes, vêem seus empenhos frustrados, e não sabem o que e como falar com seus jovens pacientes e familiares sobre o porquê da não melhora e sobre a possível morte. Há idosos que perdem cônjuges com os quais compartilharam uma vida toda e que sentem que a vida acaba por ocasião da morte, ou que sofrem de longas doenças degenerativas que causam grandes dores, limitações e sofrimento e das quais não têm com quem falar. Essas são questões cotidianas. O desenvolvimento da tecnologia médica e dos diagnósticos e tratamentos cada vez mais sofisticados trouxe o prolongamento da vida, embora nem sempre tenhamos garantia da qualidade desta, principalmente no caso dos idosos. A importância de enfocar o tema da morte está ligada ao fato de que, ao falar desta, estamos falando de vida e, ao falar de vida, a qualidade da mesma acaba sendo revista. Esta vem decaindo, em parte, pelo lugar ao qual a morte foi relegada no século XX: do interdito, do vergonhoso, do oculto - uma inimiga a ser vencida a qualquer custo. Quanto mais se nega a morte, mais esta parece fazer-se presente através da violência urbana, do crescimento do número de pessoas portadoras do HIV, do suicídio, das guerras.
Por outro lado, as estatísticas da Organização Mundial de Saúde indicam um aumento significativo no número de pessoas idosas em todo o mundo. Entretanto, esse prolongamento da vida nem sempre é acompanhado por uma preocupação equivalente com a qualidade da mesma. Do ponto de vista social, muitos idosos têm que trabalhar mesmo depois de aposentados. Muitos amargam graves dificuldades financeiras depois de trabalhar praticamente durante toda a vida, tanto pelo valor aviltante da aposentadoria quanto pela impossibilidade de exercerem atividades remuneradas, por questões de saúde, isso porque a velhice é também o período em que ocorre a incidência de muitas enfermidades, algumas longas e degenerativas, assim como surgem limitações decorrentes de perdas nas esferas física, psicológica e social.

Com o avanço da tecnologia médica, muitas doenças puderam ser eliminadas; outras, que já foram fulminantes, hoje não mais o são, ocorrendo uma cronificação das mesmas e um conseqüente prolongamento da vida. Entretanto, mesmo com a sofisticação dos tratamentos, freqüentemente são acompanhados de intenso sofrimento. Vários idosos reclamam de muitas dores, mas, com a naturalização desse processo, diz-se que é normal que adoeçam e tenham dores, aumentando ainda mais os sofrimentos!

O avanço da idade traz também a vivência de várias perdas não ligadas necessariamente a doenças e suas conseqüências. Assim, além das perdas vividas na infância e adolescência, o idoso passa a perder pessoas de sua faixa de idade, já que a morte está relacionada com a velhice. São perdas muito dolorosas, como, por exemplo, um cônjuge, com o qual se viveu toda a vida, e cuja morte pode significar o arrancar de um grande pedaço; uma vida que foi construída a dois, agora, precisa ser continuada só. Além do cônjuge, outras figuras de referência, como os amigos, também se vão, ficando presente a idéia de "que o último
O avanço da idade traz também a vivência de várias perdas não ligadas necessariamente a doenças e suas conseqüências. Assim, além das perdas vividas na infância e adolescência, o idoso passa a perder pessoas de sua faixa de idade, já que a morte está relacionada com a velhice. 
a ficar terá que apagar a luz", o temor de que não sobre mais nenhum dos amigos. Temos, também, observado um fenômeno ainda mais grave e que se torna cada vez mais comum: pais idosos perdendo filhos na fase adulta, criando-se, então, um duplo problema: lidar com a perda extremamente dolorosa do filho e também do próprio cuidador, uma vez que a este cabe acompanhar de perto o envelhecimento dos pais e deles cuidar.

Todavia, como em todas as outras fases de desenvolvimento, na velhice existem também aspectos positivos, que precisam ser destacados, se não existentes as dificuldades econômicas apontadas, ou seja, a aposentadoria pode ser vista como uma oportunidade de realização de atividades que não puderam ser realizadas antes, por falta de tempo. Nesse sentido, o envelhecimento tem sido comparado à adolescência, pela possibilidade de experimentar coisas novas, como uma nova "moratória", podendo ser descobertas novas habilidades e talentos, um tempo a ser dedicado a estudos, lazer, viagens. Essa disposição para viver a vida pode explicar o sucesso dos programas de terceira idade.

A velhice pode ser um tempo de balanço, de significação e ressignificação da vida, e também um tempo de se preparar para seu fim e para a morte - mas o que se vê é que esta última continua um tema tabu, sobre o qual não se deve falar porque poderá provocar sofrimento e, principalmente, constrangimento.

A partir do que foi exposto, propomos a ampliação do escopo da educação para a morte, fundamentada pela importância da discussão do tema numa sociedade na qual convivem a morte interdita, a busca da rehumanização da morte e a morte escancarada no cotidiano das pessoas. Em tempos atuais, os acontecimentos trazem milhares de imagens sobre a morte de pessoas anônimas, por um lado, distantes geograficamente, e, por outro, próximas quando da possibilidade de uma certa identificação, pela idade, aparência, profissão, trazendo a impressão de ser gente como a gente.

Apresentamos, a seguir, propostas para a ampliação dos espaços de reflexão sobre o tema da morte, em locais e instituições, que ainda necessitam de maior desenvolvimento.

\section{A discussão do tema da morte nas escolas}

O tema da morte não está presente nas escolas, usando-se como argumento a falta de preparo dos professores. Propomos, então, uma parceria entre as escolas e o Instituto de Psicologia, na figura do Laboratório de Estudos sobre a Morte, com as seguintes atividades:

Oferecer a disciplina Psicologia da Morte (disciplina optativa oferecida, desde 1986, no Instituto de Psicologia da USP) especialmente para os professores, ou convidá-los a freqüentarem a disciplina regularmente oferecida no Instituto;

Propor espaços de treinamento em serviço na própria escola, com módulos específicos, como, por exemplo: como falar com uma criança que sofreu a perda de pessoas significativas; como integrar uma criança gravemente enferma nas atividades didáticas e de recreação; como lidar com o suicídio de pessoa conhecida na escola;

\section{Oferecer assessoria contínua nos seguintes tópicos:}

Preparar atividades pedagógicas sobre o tema da morte;

Lidar com crianças e adolescentes que possam estar passando por situações de perda e luto; 
Propor bibliografia para subsidiar a formação dos professores nesse assunto específico;

Apresentar, discutir e preparar os professores para o uso de filmes e vídeos sobre o tema da morte.

\section{Espaços para discussão sobre a morte para público leigo}

Como a morte ainda é um tema interdito e como há poucos fóruns de discussão sobre o assunto, a não ser em ocasiões específicas, é importante oferecer cursos ou vivências para o público leigo interessado no assunto. A abertura do curso Psicologia da Morte para a terceira idade e a procura pelas vagas indica o interesse pelo tema daqueles que não são profissionais de saúde. São oferecidos cursos de curta duração, palestras ou workshops. Essas atividades propõem o desenvolvimento dos conhecimentos sobre a morte, favorecendo reflexões sobre conceitos, teorias. São oferecidas vivências, abrindo-se o contato com os próprios sentimentos, com o mundo interno e a discussão sobre a morte no cotidiano. Esses espaços podem ser abertos em postos de saúde, bibliotecas, escolas, universidades, igrejas ou quaisquer outros freqüentados por pessoas interessadas em debater o tema.

\section{Discussão sobre perdas e mortes em hospitais}

Na mentalidade da morte interdita, esta é vista como erro e fracasso. Há uma aura de silêncio que rodeia o termo entre os profissionais, o que pode ser extremamente penoso. Por outro lado, o prolongamento da vida e do tempo da doença faz com que haja maior tempo de convívio entre pacientes gravemente enfermos, familiares e equipe de cuidados, principalmente da enfermagem, com um aumento da carga de estresse e com risco de colapso.
Em 1999, iniciamos um trabalho no Hospital Universitário da USP denominado "Cuidado ao cuidador no contexto hospitalar", com os seguintes objetivos:

- Identificar as necessidades das equipes de enfermagem das UTIs, clínica médica e emergência do referido hospital;

- Promover intervenções, considerando as necessidades detectadas;

- Avaliar a influência dessas intervenções na qualidade de vida do trabalhador de enfermagem nessas unidades.

Propomos atividades que favoreçam:

- Aquecimento e sensibilização para o tema principal apontado pela equipe e as suas dificuldades principais;

Aprofundamento do tema trazido pelo grupo;

- Planejamento da ação de cuidados ao cuidador pensada pela própria equipe de trabalho, tendo em vista as suas necessidades. A metodologia utilizada durante as diversas fases do trabalho envolveu atividades em grupo, como momentos de trabalho individual que envolviam relatos verbais, atividades expressivas e role playing.

Vemos a necessidade de expandir esses espaços, propondo aos superintendentes e diretores de hospitais a implantação desses trabalhos, com o envolvimento dos vários membros da equipe de saúde para vivência, reflexão e elaboração do tema da morte e das perdas nas suas várias facetas, entre as quais:

- Como comunicar ao paciente e familiares o agravamento da doença;

Como lidar com pacientes que estejam apresentando forte expressão emocional: medo, raiva, tristeza; 
- Como desenvolver o tratamento de pacientes sem possibilidade de cura, aprofundando a questão da diferença entre curar e cuidar;

Como cuidar de sintomas incapacitantes, que causam muito sofrimento e dor;

Como abordar a família quando da aproximação da morte, como acolher os fortes sentimentos presentes nessas situações;

- Como lidar com a expressão do desejo de morrer por parte do paciente, ou da família, que não suporta ver tanto sofrimento.

\section{Grupos multidisciplinares para discussão de temas de bioética no contexto hospitalar}

A discussão dos temas relacionados à morte e ao morrer dentro dos hospitais é de fundamental importância. Entre os principais temas que merecem debate, estão: morrer com dignidade, pedidos para morrer, testamentos em vida, não implantação ou não manutenção de tratamentos com objetivo de prolongamento de vida, eutanásia, distanásia, suicídio assistido, sedação, uso de analgesia. A maioria dos hospitais tem os seus comitês de ética, favorecendo a criação de espaços de discussão, enfatizando sua característica multidisciplinar, estimulando o questionamento, a ampliação da discussão, o olhar sob vários ângulos, desencorajando respostas rápidas e simplistas, respeitando-se os princípios da bioética, observando-se várias visões sobre um mesmo tema, aceitando-se as diferenças, hierarquia dos conflitos, buscandose a definição dos termos e a clarificação da situação sob discussão. Os locais por excelência para esse tipo de discussão são os hospitais, já que é o cenário principal de mortes, por vezes com muito sofrimento e dor, e profissionais que se sentem perdidos sobre como lidar com o fim da vida e a aproximação da morte. A supervisão de casos difíceis pode servir como base para esses encontros sobre bioética. Além dos hospitais, fóruns de discussão de bioética podem ser propostos nas universidades, escolas e demais instituições de saúde e educação.

\section{Projeto Falando de Morte}

O Projeto Falando de Morte ${ }^{1}$ foi planejado contemplando-se quatro vídeos educativos como instrumentos facilitadores da comunicação em relação ao tema da morte. Como não eram conhecidos vídeos brasileiros que abordassem o tema da morte, resolvemos iniciar o projeto de sua construção sem a proposição de receitas. Ao contrário, pretendeu-se criar um espaço para facilitação da comunicação entre crianças, adolescentes, adultos e idosos, famílias e profissionais de saúde e educação diante de um tema tão complexo. Esses vídeos têm um caráter preventivo, já que abordam uma questão tão pouco falada, proporcionando, através de cenas, contato com experiências que já podem ter sido vividas e, às vezes, não elaboradas, possibilitando razão para sintomas quer no campo afetivo, quer no cognitivo, e que podem não estar sendo compreendidos. Têm também um caráter educativo, já que propõem informação e orientação para pessoas nas diversas fases do desenvolvimento. Oferecem também subsídios para profissionais, fundamentando seu trabalho com pacientes que estão vivendo experiências de morte.

Diversas obras já abordaram esse tema, incluindo traduções e obras de autores nacionais. Existem também livros para crianças, adolescentes e adultos que trazem o tema da morte com diversos enfoques. Com os livros, vídeos podem ser formas de comunicação importantes para as pessoas em várias fases do desenvolvimento, já que assistir à TV e ir ao cinema são atividades muito apreciadas. Os sistemas de comunicação, que usam os canais visual e auditivo, abordam, além da esfera cognitiva, a emocional, incluindo conteúdos informativos e de sensibilização pessoal. 
O projeto Falando de Morte compõe-se de quatro vídeos:

Falando de morte: a criança (1997); Falando de morte: o adolescente" (1 ${ }^{\text {a }}$ versão em 1999, $2^{\text {a }}$ versão -2003$)$; Falando de morte com o idoso (2002); Falando de morte com profissionais de saúde (2004).

\section{Tem como objetivos principais:}

A construção de vídeos com roteiros de texto e imagens que facilitem a sensibilização e a comunicação sobre o tema da morte;

- Investigar se os vídeos construídos são, de fato, instrumentos facilitadores para a discussão do tema da morte no domicílio, escolas, hospitais e demais instituições de saúde e educação.

\section{Falando de morte: a criança}

O primeiro vídeo da série "Falando de morte" foi elaborado para crianças, suas famílias e profissionais, tendo como princípio os pontos acima colocados. A bula que acompanha o vídeo apresenta as suas principais características. Enfoca dois aspectos da morte (a morte do outro/luto e a morte de si mesmo), procurando familiarizar as crianças com os sentimentos, dúvidas e angústias decorrentes dessas situações, mostrando que há saídas e que essas experiências podem ser compartilhadas e, em conseqüência, elaboradas.

No que se refere à morte do outro, procuramos mostrar que esta pode ocorrer e que ocorre com todos nós, das formas mais variadas. Enfatizamos a questão do vínculo. Abordamos os vários sentimentos que podem estar presentes nessa situação. Procuramos também destacar o sentimento bastante comum de culpa com relação à morte de alguém amado: essa culpa pode estar presente em todos, adultos e crianças, mas nas últimas, pela onipotência típica do pensamento infantil, pode gerar várias dificuldades, principalmente pela percepção inevitável de que a morte é irreversível. Freqüentemente surge o desejo de acompanhar a pessoa morta.

No que se refere à morte de si mesmo (principalmente nos casos em que a criança é obrigada a conviver, por longos períodos, com a doença), nosso objetivo é fazer com que a criança possa atribuir à doença um significado e perceber que determinados sentimentos estão presentes. Há o medo natural da morte, mas, com este, há o medo dos procedimentos hospitalares, muitas vezes, altamente invasivos ou mesmo dolorosos, medo da separação dos entes e coisas queridas e, nessa medida, tem o objetivo de situar as crianças quanto aos principais processos ou etapas dentro de uma instituição hospitalar. O sistema familiar, nesse momento todo ele em desequilíbrio, é de extrema importância para a criança - quais podem ser os sentimentos de pais e de irmãos ao verem a criança doente? Tentaremos também uma aproximação a essa questão.

Pelo fato de os sistemas familiar, hospitalar e social mais amplo (aí incluindo a escola) serem de extrema importância para a criança, dois outros blocos discutirão as mesmas questões, agora voltadas para: quais são as dificuldades dos pais e dos profissionais que lidam com a criança gravemente enferma? E como esses pais e profissionais podem ajudar a criança e serem ajudados?

O vídeo, que tem a duração de 50 minutos, compõe-se das seguintes partes:

Bloco I: a perda do outro - luto e a perda de si mesmo - doença;

Bloco II - a família;

Bloco III - os profissionais.

Desde o lançamento, o material tem sido divulgado entre profissionais e estudantes das áreas de saúde e educação, nas disciplinas de graduação, pós-graduação, cursos de extensão,
Pelo fato de os sistemas familiar, hospitalar e social mais amplo (aí incluindo a escola) serem de extrema importância para a criança, dois outros blocos discutirão as mesmas questões agora voltadas para: quais são as dificuldades dos pais e dos profissionais que lidam com a criança grovemente enferma? 
palestras, congressos, workshops, e tem sido distribuído pelo Brasil inteiro. O vídeo recebeu também legendas em inglês, tendo sido apresentado no Congresso da Association for Death Education, nos Estados Unidos. Foi enviado também para Inglaterra, aos cuidados do Dr. Colin Murray Parkes, especialista em luto, que teceu considerações sobre a qualidade do material.

\section{Falando de morte com o adolescente}

O segundo vídeo da série, Falando de morte com o adolescente, tem uma característica muito diferente do primeiro, procurando adequar-se à linguagem do jovem, focando principalmente os comportamentos autodestrutivos.

A adolescência é um período em que rápidas mudanças ocorrem: no corpo, no desenvolvimento da sexualidade, no pensamento, que se torna ágil, nas experiências amorosas e na escolha da vocação. É a busca da identidade. É também uma fase em que se tem como objetivo experimentar todas as "novidades", estando aí justamente o perigo. Para o adolescente, é como se a morte não existisse: há uma vivência de onipotência em sua força total. Com essa forma de pensar, um carro a 200 $\mathrm{km}$ por hora jamais se espatifa num muro, uma pipada de crack não vicia.

Infelizmente, isso não é bem verdade, pois estatísticas mostram que é na adolescência que se encontra o maior número de acidentes, de usuários de drogas e de contaminação por AIDS. É o período no qual ocorre também um grande número de suicídios. Essas são forças de vida ou de morte? Certamente não é fácil responder!

Esse vídeo usa a força de imagens para reflexão e discussão dessas questões. São cenas de esportes radicais, violência, amor, sexo, uso de drogas, acidentes e tentativas de suicídio, buscando trazer uma visão realista da situação, mostrando como a vida do adolescente pode estar por um fio. De uma forma diferente da mídia, esse vídeo traz imagens acompanhadas de questões e pontos de reflexão que permitem aos adolescentes participarem da discussão, e para que pais, educadores e profissionais de saúde possam entrar nesse universo e também criar espaços para discussão e busca de alternativas.

Longe de trazer receitas, propõe uma discussão ampla e aberta sobre os referidos temas. Sabemos que soluções não são simples, mas uma comunicação efetiva e clara favorece um aprofundamento das relações e melhor qualidade de vida.

O vídeo tem a duração de 20 minutos e pode ser assistido por adolescentes, adultos, profissionais de saúde e educação. Seu uso pode dar-se de forma didática, em sala de aula, ou informalmente. Tendo em vista tratar-se de um vídeo que objetiva a reflexão, sugerese a interrupção a cada cena que suscite questões. Para maior aprofundamento dos pontos discutidos no vídeo, sugerimos a leitura do livro "Adolescência: Vida ou Morte?", de autoria de Ingrid Esslinger e Maria Julia Kovács (Editora Ática, 1998).

O patrocínio veio pela Pró-reitoria de Cultura e Extensão da USP e pela CAPES, o que permitiu a elaboração do roteiro. A TV CULTURA, através da cessão de imagens jornalísticas, favoreceu a complementação do trabalho de filmagem.

Após o lançamento, continuamos divulgando o vídeo, fazendo-o chegar às escolas e aos seus principais beneficiários, os próprios jovens. Tem sido apresentado também em cursos, congressos, tendo sido submetido também a questionário que envolve perguntas sobre a 
qualidade do material e a sugestões para mudanças, e foi a partir delas que uma nova versão foi lançada em 2003.

\section{Falando de morte com o idoso}

É o terceiro vídeo do Projeto Falando de morte, tendo sido planejado com a mesma filosofia que embasou a criação dos outros dois da série, trazendo para o idoso, seus familiares, profissionais de saúde e educação um meio que possa facilitar a comunicação sobre o tabu da morte (e das perdas) em nossa sociedade e, mais particularmente, para esse grupo.

O vídeo tem caráter preventivo (já que aborda uma questão tão pouco falada), propiciando o entrar em contato com algumas experiências já vividas e às vezes não elaboradas, possivelmente desencadeadoras de problemas sérios, com sintomas quer no campo afetivo, quer no cognitivo, cuja causa nem sempre é evidente. Tem também um caráter reflexivo, propondo discussões e troca de experiências. O vídeo tem a duração de 30 minutos, com foco nas seguintes situações:

- Saúde e doença - "perda de si";

- "Perda do outro";

"Perda contra si" - suicídios e comportamentos auto-destrutivos.

Criamos, por meio de imagens, situações que favorecem a transmissão daquilo que pretendemos, ou seja, criar canais de comunicação sobre temas relacionados ao envelhecimento, buscando-se o aprofundamento do sentido e do significado que possam ter, abrindo espaço para que se fale das próprias perdas e as das pessoas mais significativas, assuntos esses usualmente evitados pelo constrangimento que provocam. Falando de morte com profissionais de saúde Esse vídeo traz um aprofundamento de questões que foram abordadas nos outros vídeos da série. Temas como morte no processo do desenvolvimento humano, perdas no ciclo da existência, processos de luto e suas intercorrências, suicídio e comportamentos auto-destrutivos, pacientes enfermos, o agravamento da doença e a proximidade da morte, bioética e a questão da morte, e, durante todo o transcorrer da fita, aborda-se a questão de como a morte afeta os vários profissionais de saúde na especificidade de suas práticas profissionais. Para aprofundar os conteúdos abordados, convidamos os seguintes especialistas: Dr. Leocir Pessini (teólogo), para falar de bioética e distanásia; Dr. Vicente Augusto de Carvalho (psiquiatra e psicoterapeuta), para falar de cuidado ao cuidador; Dra. Maria Helena Pereira Franco (professora e psicoterapeuta), para falar de luto; Dra Adrianna Loducca (psicóloga hospitalar), para falar de dor; Dra. Ingrid Esslinger (psicoterapeuta), para falar de suícidio, e Dra. Maria Julia Kovács (psicóloga e professora da USP), para falar sobre pacientes terminais. Esse vídeo tem a duração de 50 minutos e, tal como os anteriores, propõe-se a criar espaços de facilitação para a discussão do tema em instituições de saúde e educação para profissionais ou na formação de recursos humanos nessa área, em nível de graduação e pós-graduação.

Em continuação ao Projeto Falando de Morte, temos a intenção de criar outros recursos audio-visuais na forma de filmes ou vídeos, abordando temas como: atitudes e ritos de morte no Brasil, suicídio e comportamentos auto-destrutivos, o cuidado ao paciente gravemente enfermo e seus familiares. Pretendemos imprimir, nesses projetos, a mesma característica que desenvolvemos no projeto anterior, a saber, ser um veículo facilitador da discussão, reflexão e aprofundamento, que possa ser visto por crianças, jovens, adultos, idosos, leigos e profissionais, sem, entretanto, criar modelos ou receitas. 


\section{Assessoria aos meios de comunicação}

Estamos convivendo com várias mentalidades da morte no início do século XXI, a morte interdita, rehumanizada e escancarada. Os meios de comunicação trazem a morte escancarada, que inunda os domicílios com uma torrente de imagens que envolvem mortes nas suas mais diversas formas, nos noticiários, novelas, filmes e documentários. É inegável que a morte está presente nas guerras, acidentes e que precisam ser noticiados. O que pensamos ser importante discutir é como a imagem da morte é veiculada, primeiramente na enxurrada de imagens repetidas inúmeras vezes, e no texto que acompanha as imagens, superficial e sem continuidade. Um outro ponto assustador é que, imediatamente após um noticiário envolvendo a guerra, tragédias ou morte de pessoas ilustres, é apresentado um anúncio ou notícia que muda de assunto, levando a uma banalização da morte. Vários jornalistas têm nos procurado para entrevistas, e aproveitamos essas ocasiões para debater sobre como são veiculadas notícias envolvendo perdas e morte.

Como sabemos que a televisão, além de ser um meio de distração, é também um veículo de formação, pensamos ser importante discutir com os profissionais de comunicação a possibilidade de abrir um espaço para que os temas relacionados com a morte possam ser apresentados, acompanhados de um tempo de reflexão, com possibilidade de discussão sobre o assunto. Um outro ponto que achamos importante ser considerado é que se possa pensar numa maneira menos agressiva de mostrar a morte, ou que a morte não sirva como mercadoria cujo único objetivo seja o aumento do índice de audiência. Não se trata de eliminar ou ocultar o assunto, e, sim, de tratá-lo de uma forma mais humana.

\section{Formação de profissionais de saúde e educação}

A diferença entre as pessoas em geral e os profissionais de saúde: médicos, enfermeiros, psicólogos é que, na vida destes, a morte faz parte do cotidiano, tornando-se companheira de trabalho. Doenças com prognósticos reservados trazem uma ameaça à vida e um aceno à morte.

Negar a morte é uma das formas de não entrar em contato com as experiências dolorosas. A grande dádiva da negação e da repressão é permitir que se viva num mundo de fantasia onde há ilusão da imortalidade. Se o medo da morte estivesse constantemente presente, não conseguiríamos realizar os sonhos e projetos. Existe, no ser humano, o desejo de se sentir único, criando obras que não permitam o seu esquecimento, dando a ilusão de que a morte e a decadência não ocorrerão. Essa couraça de força é uma mentira que esconde uma fragilidade interna, a finitude e a vulnerabilidade.

Combater a morte pode dar a idéia de força e controle; entretanto, quando ocorrem perdas sem possibilidade de elaboração do luto, não há permissão para expressão da tristeza e da dor, trazendo graves conseqüências como maior possibilidade de adoecimento. É por isso que a depressão é atualmente uma doença que tem acometido os profissionais da área de saúde mental. O luto mal-elaborado está se tornando um problema de saúde pública, dado o grande número de pessoas que adoecem em função de uma carga excessiva de sofrimento sem possibilidade de que este seja elaborado. Esse mal também está afetando os profissionais de saúde, que cuidam do sofrimento alheio e que, muitas vezes, não têm espaço para cuidar da sua dor, levando ao adoecimento destes, como veremos adiante. Segundo Pessini (2001), existem dois paradigmas vinculados à ação de saúde: o curar e o cuidar. No paradigma do curar, o 
investimento é na vida a qualquer preço, na qual a Medicina de alta tecnologia se torna presente, e as práticas mais humanistas ficam em segundo plano. No paradigma do cuidar, há uma aceitação da morte como parte da condição humana, leva-se em conta a pessoa doente, e não somente a doença; enfatiza-se a multidimensionalidade da doença, a dor total, como preconiza Saunders (1991).

Ao se priorizar no hospital, o salvar o paciente a qualquer custo, a ocorrência da morte ou de uma doença incurável pode fazer com que o trabalho da equipe da saúde seja percebido como frustrante, desmotivador e sem significado. Essa percepção pode ser agravada quando os procedimentos médicos a serem realizados com pacientes, fora de possibilidade de cura, não são compartilhados com toda a equipe, sendo esse fato apontado como uma das razões principais para o estresse. Por outro lado, não conseguir evitar, adiar a morte ou não poder aliviar o sofrimento pode trazer ao profissional a vivência dos seus limites, impotência e finitude, o que pode ser extremamente doloroso (Kovács, 2003).

Educar para a morte é também preparar profissionais de saúde para lidar com ela. Perguntamo-nos se a escolha da profissão tem relação com a morte, principalmente no caso daqueles da área de saúde. Possivelmente, a primeira resposta dada será não, mas convidamos os assistentes para uma reflexão. Não será a escolha da profissão uma tentativa de preparação para lidar com a própria morte e daqueles de quem cuida? Em tempos de morte interdita, muitos jovens não tiveram contato próximo com a morte, muitos a viram pela tela da TV, com todas as distorções possíveis e sem possibilidade de interação.
Os profissionais de saúde, na sua formação, deveriam ter a possibilidade de uma educação para a morte, preparar-se para lidar com a morte daqueles que estão sob seus cuidados. Como pode ser esse preparo?

Nos dias de hoje, o que mais ouvimos nas instituições de saúde e educação é que os seus profissionais não foram preparados para lidar com a morte. Perguntamo-nos como é possível que os cursos de Medicina, de Enfermagem, de Psicologia e outros não tenham disciplinas que abordem o tema. A segunda questão que traz um contraponto a uma falta externa é saber se os estudantes e os jovens profissionais querem, de fato, preparar-se. Buscando resposta a essas questões, podemos traçar algumas reflexões. Para alguns, é mais fácil dizer que não houve preparo para enfrentar algumas situações desafiadoras, principalmente quando há perspectiva de morte próxima, com sofrimento e com familiares exigentes. Então a questão é se querem, de fato, preparar-se e como.

De nossa parte, é claro que não pretendemos dar receitas ou respostas fáceis e, sim, abrir a possibilidade de reflexão e discussão. Ao longo de nossa experiência em cursos de graduação, pós e reciclagem de profissionais em serviço, verificamos que é importante que a pessoa esteja disponível para esse preparo, pois tocar-se-á em experiências vividas, eventualmente com dor e sofrimento, retomando experiências limites, situações desconhecidas e momentos de impotência.

A educação de profissionais de saúde e educação para a morte deverá contemplar os seguintes pontos:

- Sensibilizar o aluno para os sentimentos e reflexões sobre os vários pontos
Ao se priorizar no hospital, o salvar o paciente a qualquer custo, a ocorrência da morte ou de uma doença incurável pode fazer com que o trabalho da equipe da saúde seja percebido como frustrante, desmotivadore sem significado. 
abordados no curso, como, por exemplo: suicídio, aproximação da morte, perda de pessoas da mesma faixa etária por acidentes, entre outras;

Apresentar várias abordagens teóricas sobre a questão da morte;

Refletir sobre uma prática vivida, aprendizagem que envolverá aspectos cognitivos e afetivos, buscando-se o sentido individual e o coletivo. É ter a possibilidade de fazer uma constante revisão de sua práxis, ou de seu estágio, considerando conflitos, frustrações e levando em conta o ponto de vista do sujeito na construção de seu próprio conhecimento.

Há várias modalidades que se pode propor para a formação de alunos e profissionais de saúde e educação: cursos de graduação, de pós, atualização, especialização, workshops, vivências, supervisão, grupos focais. Os grupos multidisciplinares trazem uma grande riqueza de pontos de vista e de abordagens.

O Laboratório de Estudos sobre a Morte (LEM) foi fundado em março de 2000, faz parte do Departamento de Psicologia da Aprendizagem, do Desenvolvimento e da Personalidade, do Instituto de Psicologia da USP. A justificativa para a sua criação é a importância dos estudos sobre a morte e o morrer. Por outro lado, é também a consolidação de uma área de estudo, pesquisa e assistência à comunidade envolvendo a temática da morte. Sua criação permitiu integrar docentes, profissionais, pós-graduandos e alunos da graduação em torno do tema que, como vimos, embora ainda tabu, começa a gerar frutos importantes para a formação e consolidação de uma práxis voltada para a qualidade de vida de pessoas em situações de crise, sofrimento e dor. Oferece cursos de graduação, de pós e de extensão.
Esse Laboratório congrega projetos já existentes e se propõe a abrigar novas idéias e propostas que possam resultar em projetos de pesquisa, na formação de estudantes de graduação e pós, na reciclagem de profissionais de saúde e educação bem como no atendimento à comunidade.

\section{Os seus objetivos são os seguintes:}

- Estimular a busca de conhecimento, reflexão e discussão sobre o tema da morte, nos vários ângulos acima mencionados;

Favorecer a formação de profissionais de saúde e educação sensíveis a pessoas que estão vivendo situações de perda, limite e morte nas várias fases do desenvolvimento;

- Dar prosseguimento às pesquisas na área, envolvendo alunos de graduação, pósgraduação e profissionais de saúde e educação;

Criar um banco de dados com bibliografia nacional e estrangeira atualizada como referência para estudantes e profissionais interessados no tema;

Criar espaços de atendimento à comunidade para pessoas que estão passando por situações de perda e doença.

Elencamos, neste artigo, algumas das possibilidades de educação para a morte tanto para público leigo que está vivendo situações de perda e morte quanto para profissionais que têm, sob seus cuidados, essas pessoas. Esperamos que estas propostas tragam inspiração para que novos projetos de educação para a morte se desenvolvam no Brasil. 


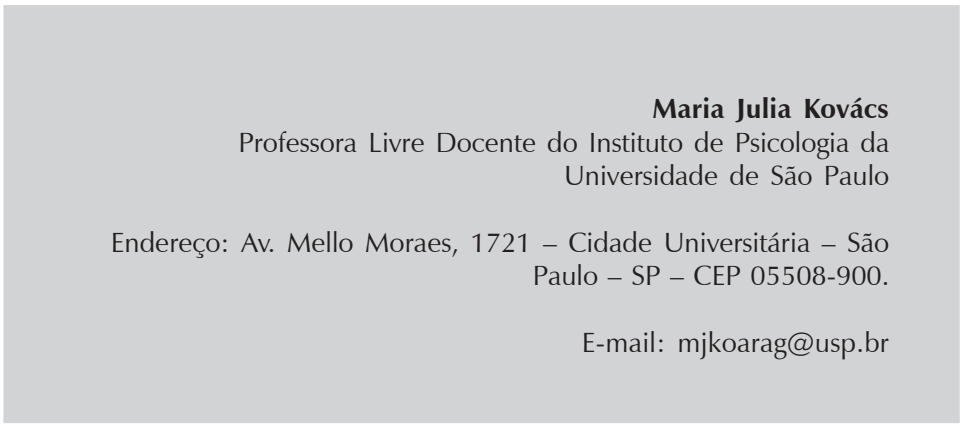

Recebido 18/05/05 Aprovado 03/11/05

ARIÉS, P. A História da Morte no Ocidente. Rio de Janeiro: Francisco Alves, 1977.

ESSLINGER, I. \& KOVÁCS, M.J. Adolescência: Vida ou Morte. São Paulo: Ática, 1998.

JUNG. C.G. Soul and Death. Collected Works, Vol.8. London: Routledge \& Keagan Paul, 1960.

KOVÁCS, M.J. Educação para a Morte. Temas e Reflexões. São Paulo: Casa do Psicólogo, 2003.
Referências 